\title{
Stapedial Artery: From Embryology to Different Possible Adult Configurations
}

\author{
(D) S. Bonasia, (D) S. Smajda, (D) G. Ciccio, and (D)T. Robert
}

\section{ABSTRACT}

SUMMARY: The stapedial artery is an embryonic artery that represents the precursor of some orbital, dural, and maxillary branches. Although its embryologic development and transformations are very complex, it is mandatory to understand the numerous anatomic variations of the middle meningeal artery. Thus, in the first part of this review, we describe in detail the hyostapedial system development with its variants, referring also to some critical points of ICA, ophthalmic artery, trigeminal artery, and inferolateral trunk embryology. This basis will allow the understanding of the anatomic variants of the middle meningeal artery, which we address in the second part of the review.

ABBREVIATIONS: MMA = middle meningeal artery; $\mathrm{OA}=$ ophthalmic artery; $\mathrm{SA}=$ stapedial artery

$\mathrm{T}$ he stapedial artery (SA) is an embryologic artery that allows the development of orbital and dural arteries, and also of the maxillary branches. Its complex embryologic development explains numerous anatomic variations of the middle meningeal artery (MMA) and orbital arteries. Few anatomists ${ }^{1-7}$ have dissected a human middle ear that bore a persistent SA and described the origin and course of this artery. Ear, nose, and throat surgeons reported cases discovered during middle ear surgeries, which explains the technical difficulties of the surgery in the presence of a persistent SA. ${ }^{8-20}$ More recently, neuroradiologists have paid particular attention to this anatomic variant. ${ }^{21-26}$ These studies, associated with the comparative anatomy, ${ }^{27-29}$ allow the understanding of the persistence of the SA. In this article, after a quick refresh concerning hyostapedial, carotid, and ophthalmic systems, the anatomic variations, including the SA, are presented and explained.

\section{History}

The first cadaveric case of persistent SA was described by $\mathrm{Hyrtl}^{30}$ in 1836, who called attention to an artery that runs across the

Received April 17, 2020; accepted after revision May 18.

From the Department of Neurosurgery (S.B., T.R.), Neurocenter of the Southern Switzerland, Lugano, Switzerland; Department of Interventional Neuroradiology (S.S., G.C.), Rothschild Foundation Hospital, Paris, France; and University of Southern Switzerland (T.R.), Lugano, Switzerland.

Please address correspondence to Thomas Robert, MD, Department of Neurosurgery, Neurocenter of the Southern Switzerland, Regional Hospital of Lugano, Via Tesserete 46, CH-6903 Lugano, Switzerland;

e-mail: thomas.robert43@gmail.com

- Indicates open access to non-subscribers at www.ajnr.org

http://dx.doi.org/10.3174/ajnr.A6738 obturator of the stapes in a human cadaver, with some similarities with a vessel found in hibernating animals. In the first half of the 20th century, the phenomenal publication by Padget, ${ }^{31}$ based on the dissections of 22 human embryos of the Carnegie collection, provided a great deal of information about the embryologic development of the craniofacial arteries and, in particular, of the hyostapedial system. In the same period, Altmann ${ }^{32}$ furnished a comprehensive explanation of the development of the aortic arches and of the carotid system variants. However, not until the 1960s, do we find the first angiographic demonstration of MMA variations and, in particular, the persistence of an SA. ${ }^{33,34}$ At the end of the 1970s, Lasjaunias was able to give a comprehensive explanation of all variations that implicate the SA. ${ }^{23,24}$ This group's more famous articles ${ }^{23-25,35-38}$ were published between 1975 and 1990 and are summarized in their textbook..$^{39}$ Diamond $^{5,27,28}$ also published some articles based on the comparative anatomy, principally with the great apes, that increased our understanding of the stapedial system. In these past 3 decades, a few case reports of interesting anatomic variations that implicate the SA were published. ${ }^{17,40-47}$

\section{Comparative Anatomy}

The studies of comparative anatomy were fundamental in the understanding of the embryologic development of the SA. At the beginning of the 20th century, Tandler, ${ }^{48}$ when studying the SA development in rats, explained the SA regression and the role of the external carotid artery in the formation of the MMA. Rats differed from human embryos because the supraorbital branch of the SA is primarily dependent on the first aortic arch (mandibular branch). Fuchs, ${ }^{49}$ in the rabbit, also showed that the first 2 


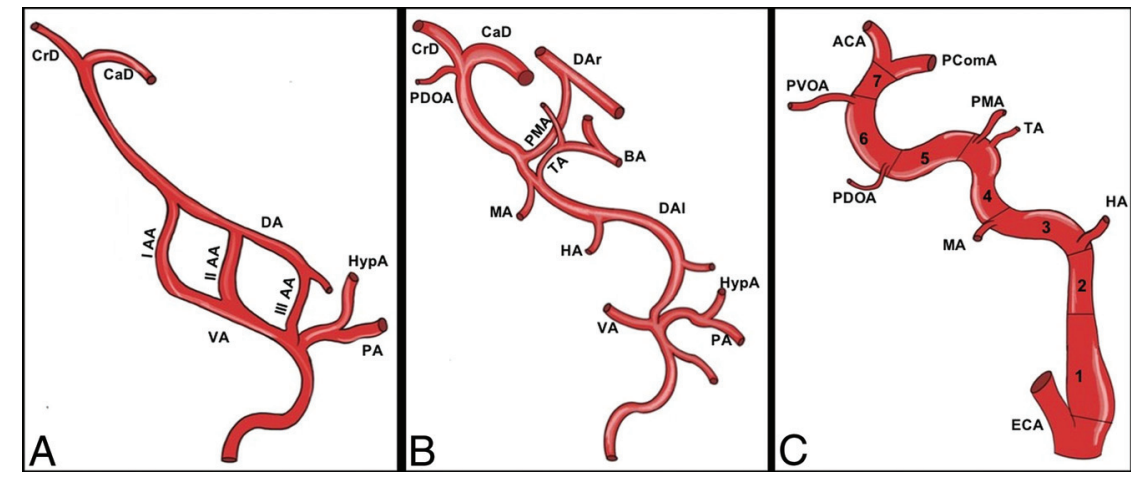

FIG 1. Embryologic segments of the ICA. Consecutive stages of ICA embryologic development. The first stages of development $(A)$ are characterized by the presence of 3 aortic arches that link the ventral aorta (VA) and the dorsal aorta (DA). The VA regresses together with the ventral part of the aortic arches. The dorsal remnants of the aortic arches persist as embryonic arteries. These embryonic arteries divide the ICA into 7 embryologic segments: 1) the cervical segment: it derives from the remnant of the third aortic arch (III AA); 2) the ascending intrapetrous segment: it is the remnant of the DA between the second (II AA) and third (III AA) aortic arches; the division point between segments 2 and 3 is at the point of origin of the hyoid artery (HA), that is, the dorsal remnant of the second aortic arch (II AA); 3) the horizontal intrapetrous segment: it is the remnant of the DA between the first (I AA) and second (II AA) aortic arches; the division point is at the point of origin of the mandibular artery (MA), which corresponds to the dorsal remnant of the first aortic arch (I AA); 4) the intracavernous ascending segment: it originates from the DA between the first aortic arch (I AA) and the primitive maxillary artery (PMA), which connects the DA of the 2 sides (dorsal aorta left [DAl]; dorsal aorta right [DAr]). The trigeminal artery origins at the junction between the segment 4 and 5 of the ICA; this latter represents a primitive connection between the cavernous ICA and the basilar artery (BA); 5) the horizontal intracavernous segment: it derives from the DA between the PMA and the primitive dorsal OA (PDOA); 6) the clinoid segment: it corresponds to the DA between the PDOA and the primitive ventral OA; and 7) the terminal segment: the terminal ICA between primitive ventral OA and the primitive ICA bifurcation into the future anterior cerebral artery (ACA) and the future posterior communicating artery (PComA). The figure also shows the hypoglossal artery (HypA) and the proatlantal artery (PA), which originate proximal to the third aortic arch and will contribute to the formation of the external carotid artery (ECA) branches.

aortic arches participate in the formation of the external carotid artery as in human embryos. More recently, Diamond ${ }^{28}$ and Falk $^{29}$ compared the development of the SA between human and great ape embryos and highlighted some analogies.

\section{Embryology}

The development and regression of the SA is strictly related to some embryonic systems. In this part of our article, we summarize the main steps of the ICA and ophthalmic artery (OA) development. We present a more-detailed description of the hyostapedial system to understand the different possible adult variations related to this artery.

The Carotid System. Because a detailed description of the ICA embryologic development is beyond the scope of this article, we focused only on the understanding of the "aberrant flow of the ICA." It consists of an intratympanic course of the ICA and could be associated with a persistent SA and consequent variation in the origin of the MMA. The principal steps of ICA development are summarized in Fig 1.

In the first stage of Padget (4-5 mm embryos), the first 2 aortic arches initiate their natural regression, which allows the ICA to be individualized. The embryologich segments of the ICA are derived from the third aortic arch and from the dorsal aorta cranial to the third aortic arch. ${ }^{31,32,39}$ The dorsal aorta also regresses at the same time between the third and fourth aortic arches. In terms of embryology, the ICA was divided by Lasjaunias and Santoyo-Vazquez ${ }^{50}$ into 7 different segments. The first segment corresponds to the third aortic arch from the origin of the ventral pharyngeal artery (the future external carotid artery) to the junction between the third aortic arch and the dorsal aorta. The second segment is the dorsal aorta between the second and third aortic arch. The third segment is the dorsal aorta between the first and second aortic arch. The fourth segment is the dorsal aorta between the first aortic arch and the origin of the trigeminal artery (and the primitive maxillary artery). The fifth segment is the dorsal aorta between the origin of the trigeminal artery (and the primitive maxillary artery) and the origin of the primitive dorsal OA (the future inferolateral trunk). The sixth segment is between the origin of the primitive dorsal $\mathrm{OA}$ and the origin of the primitive ventral OA. The seventh segment is between the primitive ventral $\mathrm{OA}$ and the primitive carotid bifurcation. ${ }^{23,24,31,39}$

It is important to note that the carotid bulb does not have the same embryologic origin as the other segments of the ICA. It originates from the pharyngo-occipital system, which easily explains variations in origin of the ascending pharyngeal and occipital arteries. Agenesis or abnormal regression of $\geq 1$ segment of the ICA explains an intratympanic course of the ICA ${ }^{12}$ (by pharyngo-carotid anastomosis) and also the different type of "reperfusion" in the case of ICA agenesis. ${ }^{32}$ The intratympanic course of the ICA, also named as an "aberrant flow of the ICA," is the consequence of the abnormal regression of the first and second segments, with anastomosis between the inferior tympanic artery (from the ascending pharyngeal artery) and the caroticotympanic artery (from the carotid artery) that distally infuses the ICA. The pseudo-ICA, consequently, has an intratympanic course without passing through the stapes. ${ }^{12,39,51}$

Hyostapedial System. "Hyostapedial artery" is the term used to describe the complete embryologic development of the second aortic arch. The SA, which develops from the hyoid artery and takes its name after passing through the crus of the stapes, is an embryonic artery present between Padget ${ }^{31}$ stages III and VI (9-24 mm). This is an important embryologic system from which numerous dural, orbital, and facial arteries develop. The steps of SA development are summarized in Table 1. 


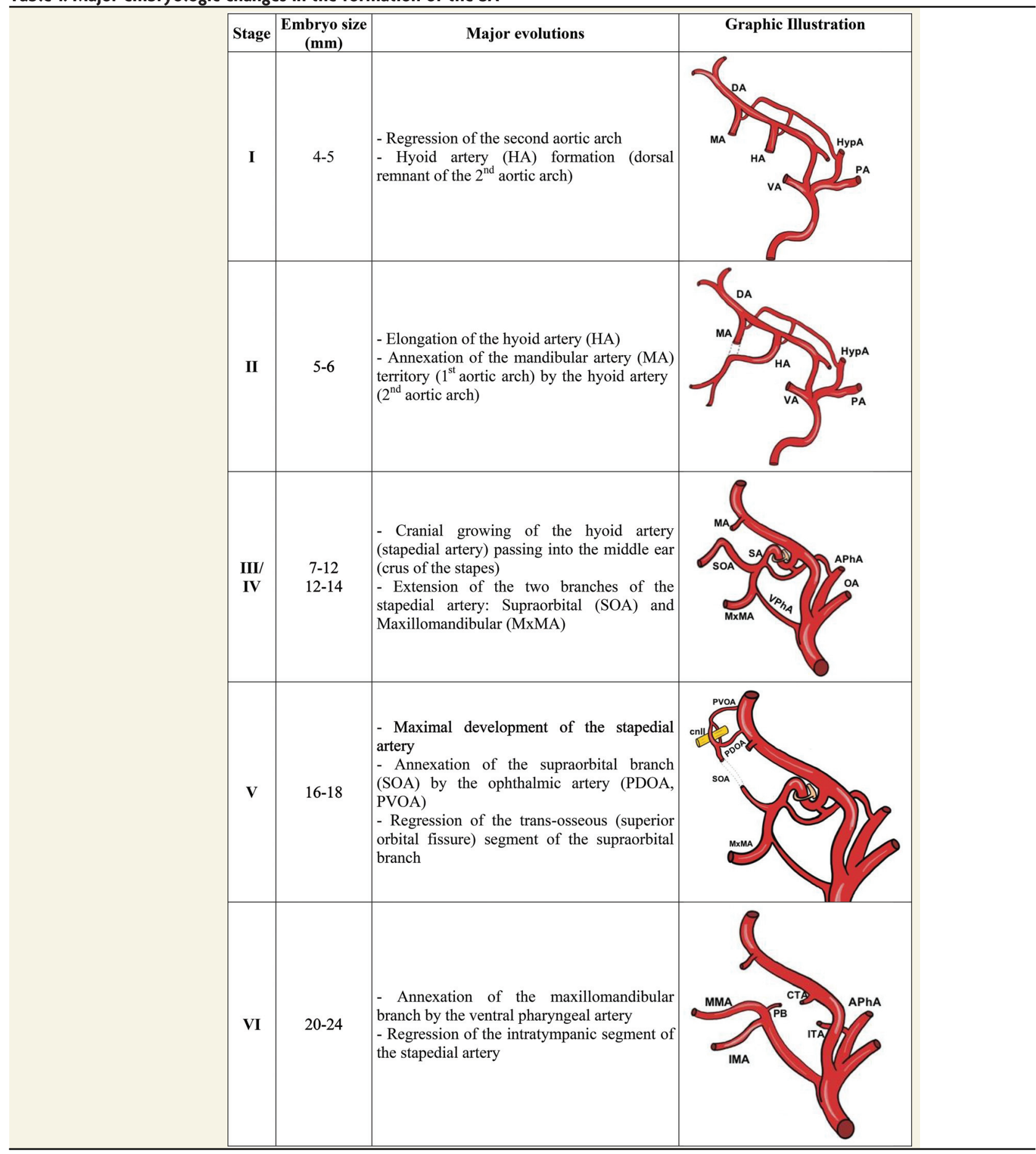

The hyoid artery is the dorsal remnant of the second aortic arch, which regresses early in the embryologic development (4-5 $\mathrm{mm}$, Padget ${ }^{31}$ stage I). ${ }^{2,12}$ After this arch regression, at approximately the 5-6-mm stage (Padget ${ }^{31}$ stage II), the hyoid artery presents a rapid lateral elongation between the beginning of the 7th and 19th weeks of gestation, when it gives an anastomosis to the mandibular artery (remnant of the first aortic arch). ${ }^{31}$ During Padget $^{31}$ stage III (7-12-mm embryos), the hyoid artery is prominent and grows cranially, passing, as the SA, through the crus of the stapes. In contrast, the mandibular artery is short and difficult to identify. During this stage, the initial forms of the 2 main branches of the SA (supraorbital and maxillomandibular divisions) are visible, even if they are definitively established only in Padget $^{31}$ stage IV (12-14 mm).

At the $16-18-\mathrm{mm}$ stage (Padget ${ }^{31}$ stage V), the SA continues its elongation to the gasserian region, passing into the future tympanic cavity and, particularly, through the crus of the stapes, reaching its maximum development. ${ }^{23,31,32}$ The supraorbital artery, which follows the ophthalmic root of the trigeminal nerve, allows the development of orbital branches (supraorbital, 
Table 2: Summary of embryologic steps of the stapedial and ophthalmic systems

\begin{tabular}{|c|c|c|}
\hline Stapedial System & Embryo Size (mm) & Ophthalmic System \\
\hline $\begin{array}{l}\text { Regression of the second aortic arch; hyoid } \\
\text { artery formation (dorsal remnant of the } \\
\text { second aortic arch) }\end{array}$ & $4-5$ & $\begin{array}{l}\text { Primitive maxillary artery as temporary } \\
\text { branch; primitive dorsal OA appearance }\end{array}$ \\
\hline $\begin{array}{l}\text { Elongation of the hyoid artery; annexation } \\
\text { of the mandibular artery (first aortic arch) } \\
\text { by the hyoid artery (second aortic arch) }\end{array}$ & $5-6$ & $\begin{array}{l}\text { Primitive hyaloid artery }=\text { plexiform } \\
\text { channels; primitive ventral OA } \\
\text { appearance }\end{array}$ \\
\hline $\begin{array}{l}\text { Cranial growing of the hyoid artery (SA) } \\
\text { passing into the middle ear (crus of the } \\
\text { stapes) }\end{array}$ & $7-14$ & $\begin{array}{l}\text { Formation of primitive hyaloid and } \\
\text { common ciliary arteries }\end{array}$ \\
\hline $\begin{array}{l}\text { Maximum development of the SA; } \\
\text { extension of the } 2 \text { branches of the SA, } \\
\text { supraorbital and maxillomandibular }\end{array}$ & $16-19$ & $\begin{array}{l}\text { Migration in origin of the primitive ventral } \\
\text { OA; regression of the primitive dorsal } \\
\text { OA; formation of the anastomotic ring }\end{array}$ \\
\hline $\begin{array}{l}\text { Regression of the transosseous (superior } \\
\text { orbital fissure) segment of the } \\
\text { supraorbital branch }\end{array}$ & $20-24$ & $\begin{array}{l}\text { Ventral interruption of the anastomotic } \\
\text { ring; annexation of the supraorbital } \\
\text { branch by the OA }\end{array}$ \\
\hline
\end{tabular}

lacrimal, ethmoids, and frontal arteries) and also of the MMA. ${ }^{39}$ The maxillomandibular artery exits the cranial cavity through the foramen spinosum and, extracranially, gives its 2 branches: infraorbital and mandibular arteries (the future infraorbital and inferior alveolar arteries). After this maximum development of the SA, 2 annexations and 2 regressions occur to give the adult configuration of the MMA. Intracranially, the orbital branches are annexed by the primitive $\mathrm{OA}$ and the trans-sphenoidal segment of the supraorbital branch regresses, leaving an anastomotic artery between the anterior branch of the MMA and the lacrimal artery (the sphenoidal artery), which penetrates the orbit through the superior orbital fissure. Extracranially, the ventral pharyngeal artery annexes the maxillomandibular artery of the SA, forming the proximal stem of the MMA and becoming the external carotid artery. Consequently, by flow reversal into the SA, its tympanic portion regresses and leaves, as remnants, the caroticotympanic artery (from the ICA) and the superior tympanic artery (from the petrous branch of the MMA). These annexations and regressions with regard to the SA happen during Padget ${ }^{31}$ stage VI (20-24-mm embryos). ${ }^{31,39}$

OA. The embryogenesis of the primitive $\mathrm{OA}$ is related in some phases to the hyostapedial systems. These phases are summarized and related to the concomitant SA steps of development presented in Table 2. The formation of the OA depends on 2 different arteries during the 4-18-mm stages; the primitive dorsal OA and the primitive ventral OA. The primitive dorsal OA develops from the cavernous segment of the primitive ICA and the primitive ventral OA develops from the anterior division of the primitive ICA. The primitive dorsal OA penetrates the orbit through the superior orbital fissure and the primitive ventral OA penetrates through the optic canal.

Next, 2 major anastomoses between these 2 arteries are formed. The first one is an intraorbital plexiform anastomosis supplied by the 2 arteries around the optic nerve (the future second segment of the OA). The second anastomosis is intradural between the primitive ventral OA and the primitive ICA to form the definitive supraclinoidal origin of the OA. The proximal portion of the primitive ventral OA (between its origin on the ACA and its anastomosis with the ICA), then regresses to give the adult stem of the OA.
In the following step, the proximal part of the primitive dorsal OA regresses and its remnant becomes the inferolateral trunk of the primitive ICA. Concomitantly, in 7- and 24-mm embryos (stages III-VI of Padget), the SA arises from the primitive hyoid arch of the petrous ICA. As described above, its supraorbital artery enters the orbit to give orbital branches. It divides into 2 different branches: the ethmoidonasal and lacrimal arteries. The ethmoidonasal artery anastomoses with the primitive $\mathrm{OA}$ at the arterial ring around the optic nerve, as previously described. The trans-sphenoidal part of the supraorbital artery then regresses, and its orbital branches are annexed by the primitive OA to give the adult conformation.

Trigeminal Artery. The trigeminal artery represents one of the carotid-basilar anastomoses, which appears in 4-5-mm embryos (Padget $^{31}$ stage I) and disappears in 12-mm embryos (Padget ${ }^{31}$ stage III). It origins from the basilar artery, between the superior and the anteroinferior cerebellar arteries, passes medial to the gasserian ganglion, and follows the trigeminal nerve to the primitive ICA at the level of the junction between the fourth and fifth segments of the ICA. The trigeminal artery has a common origin on the ICA with the primitive maxillary artery. The carotid remnant of these 2 primitive arteries will be the future meningohypophyseal trunk, from which the lateral clival, marginal tentorial, and inferior hypophyseal arteries will originate. ${ }^{31,32}$ The basilar remnant of the trigeminal artery could be considered responsible for MMA possible origin from the basilar artery. In fact, when this trigeminal remnant anastomoses with a persistent SA, the final MMA will arise from the BA. The details of this variant are explained in Part 2 of our article.

Formation of the Inferolateral Trunk. As supported by the theory of Lasjaunias, ${ }^{23,24,39}$ with regard to the embryology of the $\mathrm{OA}$, the inferolateral trunk is the carotid remnant of the primitive dorsal OA. The primitive dorsal OA develops from the cavernous segment of the primitive ICA and penetrates the orbit through the superior orbital fissure. In 40-mm embryos, the proximal part of the primitive dorsal OA regresses, and its remnant becomes the inferolateral trunk. At the adult configuration, the inferolateral trunk is composed of 4 branches: 1) superior branch, which supplies the roof of the cavernous sinus; 2) anteromedial branch, 


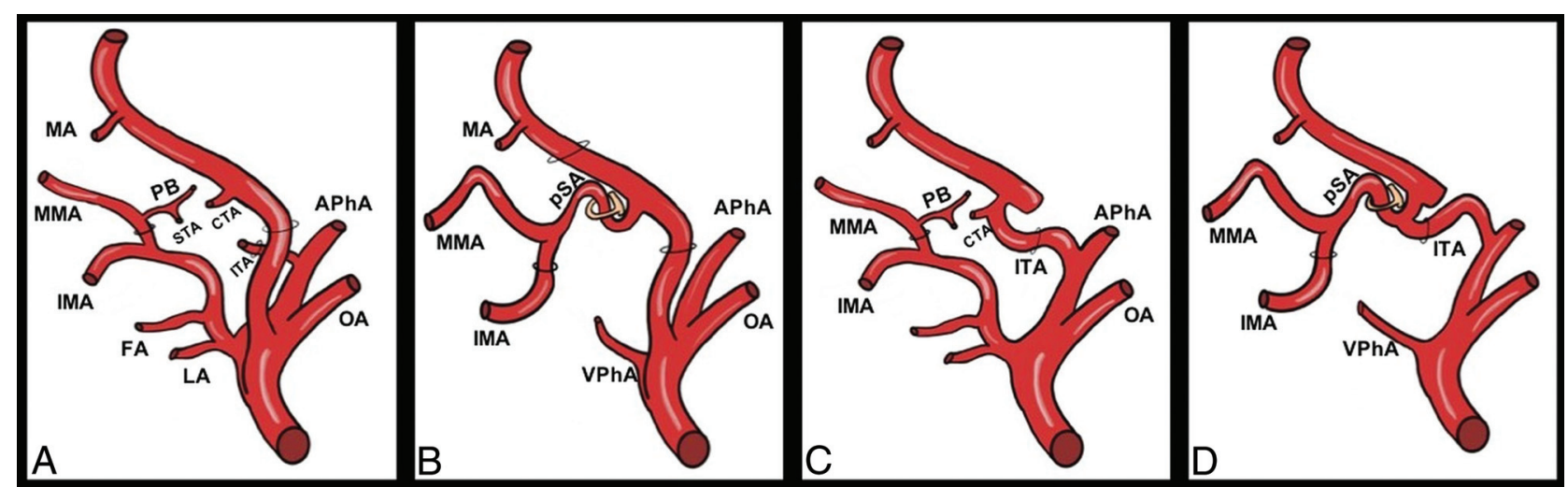

FIG 2. Persistent SA and intratympanic flow of the ICA. A, The normal regression process of the hyostapedial system. After the SA proximal regression, its proximal remnant originates from the ICA as the carotico-tympanic artery (CTA). Its distal part is annexed by the ventral pharyngeal artery, the future external carotid artery, to give the internal maxillary artery its first and major branch, the middle meningeal artery (MMA). The MMA side of the SA persists as the petrosal branch (PB), which gives birth to the superior tympanic artery (STA). The anastomotic branch to the hyostapedial system from the ascendant pharyngeal artery (APhA) persists as the inferior tympanic artery (ITA). The CTA, STA, and ITA contribute to the adult vascularization of the middle ear. B, Persistent SA. In the case of complete SA persistency, this artery originates from the petrous ICA and gives, intracranially, the MMA, and the internal maxillary artery exits the middle fossa skull base through the foramen spinosum as the extracranial branch. This variant is due to the lack of annexation of the maxillary-mandibular branch by the ventral pharyngeal artery. $C$, Pseudopetrous or aberrant intratympanic ICA. This variant is due to the agenesis of the cervical ICA (third aortic arch). The cervical ICA agenesis is bypassed through a hypertrophic inferior tympanic artery, which courses from the APhA through the inferior tympanic canal and reaches the CTA. The intratympanic ICA flow is called "aberrant" because the artery does not course into its usual canal but into an enlarged inferior tympanic canal. D, Pseudopetrous ICA with or without SA persistency. This variant is due to 2 phenomena: the agenesis of the cervical ICA and SA persistency. In this case, the ITA does not reach the CTA but the persistent SA (pSA).

which passes into the superior orbital fissure; 3) anterolateral branch, which runs into the foramen rotundum; and 4) posterior branch, which passes medial to the gasserian ganglion. These branches present numerous anastomoses in the cavernous region, which correspond to the remnants of the primitive trigeminal artery, $\mathrm{OA}, \mathrm{SA}$, and maxillary artery. ${ }^{15}$

\section{Persistence of the SA}

Changes in the events previously described can determine different adult configurations of the arteries related to the hyostapedial system, such as the persistence of the SA. The incidence of this variant is estimated to be $0.48 \%$ after a series of $>1000$ temporal bone dissections. ${ }^{6}$ The possible variants related to the persistence of the SA are illustrated in Fig 2, including the rarer association of SA persistence with the so-called pseudopetrous ICA.

\section{Complete Persistence of the SA}

The complete persistence of the SA is a very rare variant, and only 2 cases were published in the context of an ICA aneurysm ${ }^{25}$ or PHACE (posterior fossa malformations, hemangioma, arterial anomalies, coarctation of the aorta/cardiac defects, and eye abnormalities) syndrome. ${ }^{39}$ In these cases, the SA could be seen as in the embryo, taking its origin from the petrous ICA, passing through the middle ear, and giving its 2 branches: one intracranial, which corresponds to the MMA, and the other extracranial, leaving the cranial cavity through the foramen spinosum. Consequently, the foramen spinosum is enlarged, the cochlear promontory is eroded, and the internal maxillary artery arises from the SA instead of the external carotid artery. Such an anatomic variant could easily be explained by the embryology and, particularly, by the absence of annexation of the maxillomandibular branch (of the SA) by the ventral pharyngeal artery.
Consequently, in the absence of reversion of the arterial flow into the SA, its proximal (intratympanic) stem could not regress. ${ }^{39}$

\section{Partial Persistence of the SA}

The partial persistence of the SA is more frequent ${ }^{1,7,21-24,26,32,52,53}$ and, in this case, only the intracranial branch of the SA keeps its origins from the petrous ICA. The foramen spinosum is absent (an orifice does not exist without its contents) or reduced in size and the MMA arises from the SA instead of the internal maxillary artery. This variant is explained by the regression of the proximal part of the maxillomandibular artery instead of the proximal part of the SA. ${ }^{39}$ A rare case of a bilateral partial persistent SA is illustrated in Fig 3. We note that it is surprising that the complete persistence of the SA is much rarer than its partial persistence. The reasons of this phenomenon are still unknown, and are probably related to some unknown phases of the annexation of the maxillomandibulary branch by the ventral pharingeal artery.

\section{Persistence of the SA Associated with Aberrant Flow of the ICA (Pseudo-Petrous ICA)}

In rare cases, ${ }^{12,21,23,24,54,55}$ the persistence of the SA is associated with an intratympanic course of the ICA (also known as "aberrant flow of the ICA"). This association of vascular variants with regard to both carotid and hyostapedial systems was described anatomically and angiographically. ${ }^{32,39}$ In these cases, the ICA enters the skull base through an enlarged inferior tympanic canal (narrowing of the vessel on DSA), passes into the tympanic cavity to bend anteriorly, and reaches its normal carotid canal. The MMA arises from the ICA in its tympanic segment and passes through the stapes to have the same course described in the previous paragraph. The exocranial orifice of the carotid canal, 


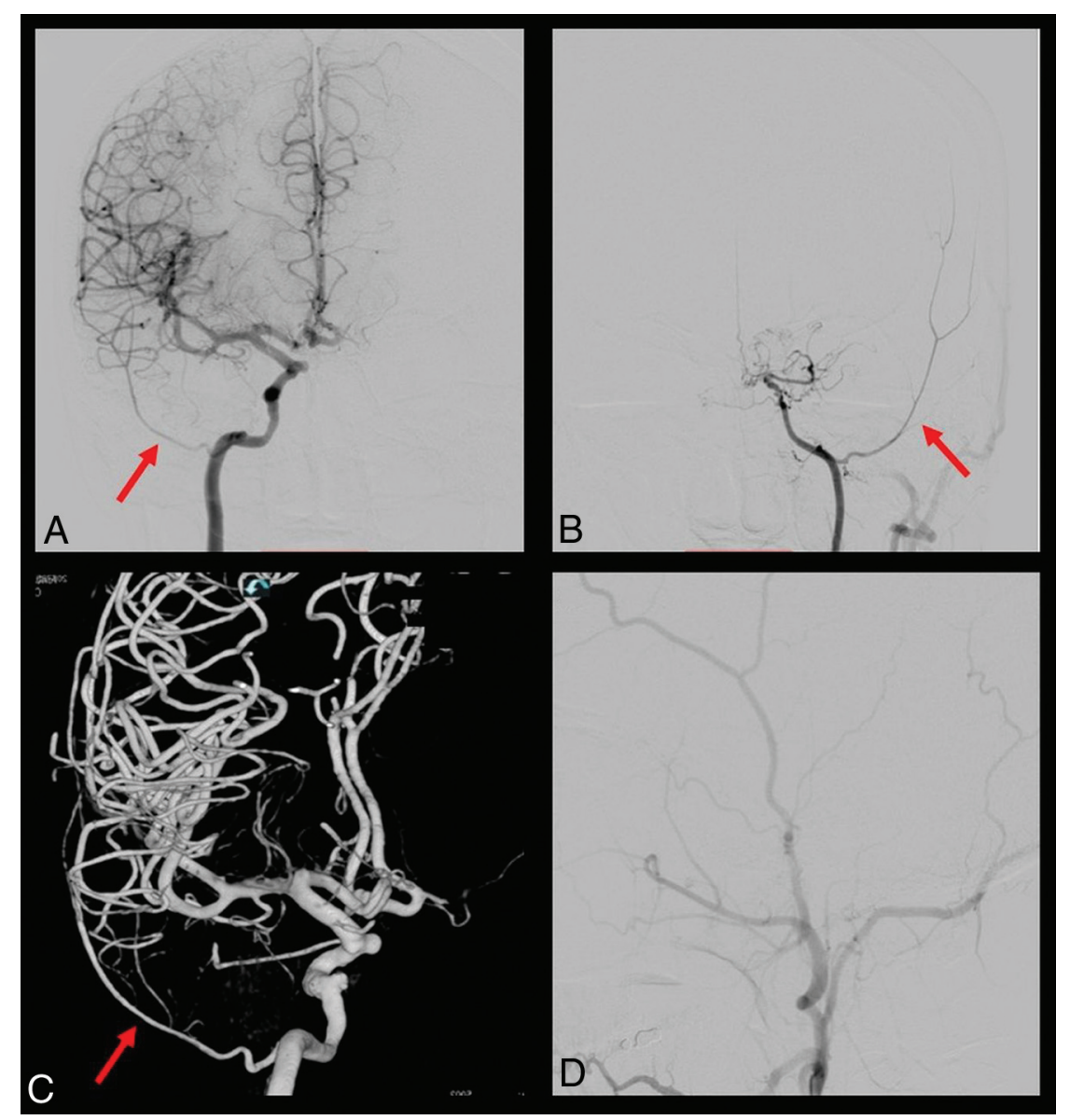

FIG 3. DSA with a bilateral partial persistent SA in a patient with Moyamoya disease. $A$ and $B$, show the right and left ICA injection, respectively, with the MMA (red arrow) arising from the petrous ICA. This phenomenon is possible because of bilateral SA persistency. $B$, The ICA is narrowed and stopped at the level of the OA due to Moyamoya disease. C, A 3D reconstruction of the right ICA from which the MMA originates (red arrow). D, The left external carotid artery injection without the MMA enhancement because of its absence.

and only 1 similar case was published by Baltsavias et al. $^{42}$ The MMA arises from the cervical portion of the ICA, ascends along the cervical ICA, enters into the tympanic cavity through the inferior tympanic canal, and follows the usual course of the SA. The 2 cases described were presented as "partial" persistence of the SA, with only the MMA arising from the SA, and the absence of the foramen spinosum. In this variant, an annexation of the SA by the inferior tympanic artery (the branch of the ascending pharyngeal artery), with regression of the proximal part of the SA explains this vascular configuration. Therefore, the SA arises from the cervical instead of the petrous segment of the ICA.

\section{MMA Origin of the $O A$}

The first description of orbital branches arising from the MMA was published in 1872 by Curnow. ${ }^{56} \mathrm{He}$ already noted in his case dissection that all orbital branches were supplied by the MMA except the central retinal artery, which kept its origin from the supracavernous ICA. Twenty years after this first description, Musgrove ${ }^{57}$ presented another case of an MMA origin of the OA, also where the central retinal artery was supplied by the MMA and the ICA does not give any orbital artery, thus the orbit is vascularized by the MMA. After other iso-

therefore, is absent in these cases. $^{23,24}$ The intratympanic course of the ICA is explained by the agenesis of the first 2 segments of the primitive ICA. The cervical segment, in fact, is the ascending pharyngeal artery with a hypertrophied inferior tympanic artery that maintains its anastomosis with the caroticotympanic artery (the branch of the ICA) into the tympanic cavity. The correct term for this aberrant flow of the ICA, in reality, is a tympano-caroticotympanic variant. ${ }^{39}$ It bypasses the absence of the cervical ICA and provides a collateral circulation to the remainder of the ICA. Therefore, the cervical and intratympanic segments of this artery do not derivate from the carotid system but from the pharyngo-occipital and hyostapedial systems (pseudo-ICA). ${ }^{23,24,39}$ The agenesis of the first 2 segments of the ICA could be partial, and the ICA seems duplicated. ${ }^{54}$

\section{Pharyngo-Tympano-SA}

This very rare variant was first described by Lasjaunias et $a l,{ }^{23}$ in 1977, in their original publication. The same case served as an illustration in the textbook, Surgical Neuroangiography, ${ }^{39}$ lated cases found during cerebral or orbital dissections, ${ }^{1,27,58,59}$ Hayreh and Dass ${ }^{60}$ reported 6 cases among their 170 orbital dissections in which the MMA participated completely (2 cases) or partially (4 cases) in the orbital supply. Moret et $\mathrm{al}^{36}$ and Lasjaunias et $\mathrm{al}^{23}$ described with precision the contribution of the MMA to the orbital vascularization and gave us a more comprehensive explanation of this anatomic variation.

The incidence of OA that arises from the MMA and penetrates the orbit through the superior orbital fissure is estimated as between 1.4 and $2.5 \% .^{60}$ In this anatomic variation, orbital arteries are supplied by the anterior division of the MMA passing through the superior orbital fissure or through the spheno-orbital foramen. The central retinal artery generally keeps its vascular supply from the supracavernous ICA, but, in a few cases, the central retinal artery is also supplied by the MMA without ICA participation. ${ }^{61} \mathrm{~A}$ case of a complete supply of the orbital arteries by the MMA is illustrated in Fig 4.

As explained before, during the embryogenesis, the SA gives the supraorbital branch, which allows the development of the lacrimal artery and anastomoses with the OA around the optic nerve 
(participation of the perioptic circle). The proximal part of the supraorbital branch then normally regresses and the lacrimal artery is annexed by the OA. ${ }^{39}$ The persistence of MMA branches (or, in extremis, the MMA origin of the OA) could be explained by 2 different phenomena: the absence of an anastomosis between the supraorbital branch and the OA, with a consequent persistence of a dual supply of the orbital arteries, or the persistence of the proximal stem of the supraorbital branch of the SA, with regression of the primitive OA (complete MMA origin of the OA). Although the supraorbital branch bifurcates (lacrimal artery laterally and ethmoido-nasal medially) usually inside the orbit, in $30 \%$ of cases, it can divide outside the orbit in the middle cranial fossa. In such cases, the ethmoido-nasal artery passes through the superior orbital fissure, but the lacrimal artery penetrates the orbit through its own canal, the spheno-orbital foramen (canal of Hyrtl, lacrimal foramen, sinus canal). The medial branch, passing through the superior orbital fissure, is named the recurrent meningeal artery in its intraorbital segment and sphenoidal artery in its intracranial segment. ${ }^{23,31,39,60}$

\section{CONCLUSIONS}

All the anatomic variations linked to the development of the SA, summarized in Table 3, could have a clinical impact. Because each vascular segment that regresses during embryologic life usually persists as an anastomosis between 2 arteries, the knowledge of the embryology and the presence of these anastomoses is of para-

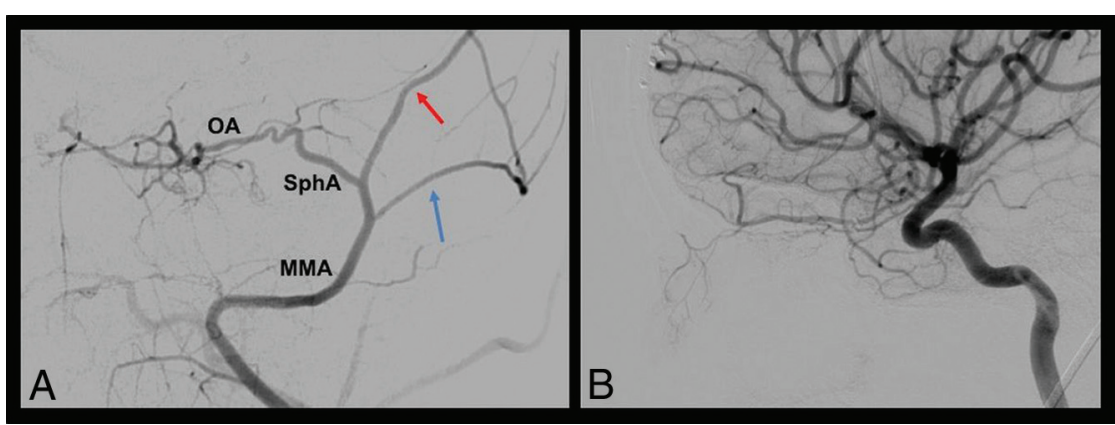

FIG 4. The MMA origin of the OA: a case of a complete OA origin from the MMA. The selective injection of the MMA in the anteroposterior projection $(A)$ shows that the sphenoidal artery (SphA) arises from the MMA after its bifurcation into the anterior (red arrow) and posterior division (blue arrow). It courses along the inner surface of the temporal and sphenoidal bone and enters the orbit through the superior orbital fissure (SOF) to give rise to the OA. B, An oblique ICA injection, highlighting the absence of the OA. mount importance in case of external carotid branch embolization. Each residual anastomosis represents a potential undesired leak of liquid embolic agent, with possible clinical implications. Knowledge of the embryologic variants described in this article represents the basis to understand the different possible adult configurations of the MMA and their clinical implications. The most common pathologies, whose treatment requires a detailed knowledge of MMA embryology and variants, are dural AVFs, meningeal tumors, and chronic subdural hematomas. Our purpose, therefore, is to give a detailed description of these variants and their clinical implications in the second part of our article.

Table 3: Anatomic variations implicating the SA

\begin{tabular}{|c|c|c|c|c|}
\hline \multicolumn{3}{|c|}{ Anatomic Variations } & \multicolumn{2}{|l|}{ Embryologic Implications } \\
\hline Type & Incidence & Direct and Indirect Signs & Embryologic Explanation & $\begin{array}{l}\text { Embryo } \\
\text { Size }(\mathrm{mm})\end{array}$ \\
\hline $\begin{array}{l}\text { Complete persistence } \\
\text { of the SA }\end{array}$ & 2 cases & $\begin{array}{l}\text { Petrous ICA origin of the MMA; petrous } \\
\text { ICA origin of the internal maxillary } \\
\text { artery; enlarged foramen spinosum; } \\
\text { eroded cochlear promontory }\end{array}$ & $\begin{array}{l}\text { Lack of annexation of the } \\
\text { maxillomandibular branch by the } \\
\text { ventral pharyngeal artery; persistence } \\
\text { of the tympanic segment of the SA }\end{array}$ & 24 \\
\hline $\begin{array}{l}\text { Partial persistence of } \\
\text { the SA }\end{array}$ & $0.4 \%$ & $\begin{array}{l}\text { Petrous ICA origin of the MMA; absent } \\
\text { foramen spinosum; enlarged facial } \\
\text { canal }\end{array}$ & $\begin{array}{l}\text { Regression of the proximal segment of } \\
\text { the maxillomandibular branch; } \\
\text { persistence of the tympanic segment } \\
\text { of the SA }\end{array}$ & 24 \\
\hline $\begin{array}{l}\text { Tympano-carotico- } \\
\text { tympanic variant; } \\
\text { aberrant flow of the } \\
\text { ICA plus persistent } \\
\text { SA }\end{array}$ & 5 cases & $\begin{array}{l}\text { Intratympanic course of the ICA; } \\
\text { petrous ICA origin of the MMA; } \\
\text { enlarged inferior tympanic canal; } \\
\text { absent exocranial carotid canal }\end{array}$ & $\begin{array}{l}\text { Regression of the proximal segment of } \\
\text { the maxillomandibular branch; } \\
\text { persistence of the tympanic segment } \\
\text { of the SA; agenesis of the first } 2 \\
\text { segments of the ICA; anastomosis } \\
\text { between inferior tympanic artery and } \\
\text { caroticotympanic artery }\end{array}$ & $24 ; 4-5$ \\
\hline $\begin{array}{l}\text { Pharyngo-tympano- } \\
\text { stapedial variant }\end{array}$ & 2 cases & $\begin{array}{l}\text { Cervical ICA origin of the MMA; absent } \\
\text { foramen spinosum }\end{array}$ & $\begin{array}{l}\text { Regression of the proximal segment of } \\
\text { the maxillomandibular branch; } \\
\text { persistence of the tympanic segment } \\
\text { of the SA; anastomosis between the } \\
\text { inferior tympanic artery and the } \\
\text { caroticotympanic artery }\end{array}$ & 24 \\
\hline MMA origin of the $O A$ & $\mathrm{n}=2 \%$ & $\begin{array}{l}\text { MMA origin of the OA; no OA from the } \\
\text { ICA or only the central retinal artery }\end{array}$ & $\begin{array}{l}\text { Lack of annexation of the supraorbital } \\
\text { branch by the OA; persistence of the } \\
\text { sphenoidal part of the supraorbital } \\
\text { branch }\end{array}$ & 24 \\
\hline
\end{tabular}




\section{REFERENCES}

1. Fisher AG. A case of complete absence of both internal carotid arteries, with a preliminary note on the developmental history of the stapedial artery. J Anat Physiol 1913;48(pt 1):37-46 Medline

2. Kelemen G. Arteria stapedia, in bilateral persistence. AMA Arch Otolaryngol 1958;67:668-77 CrossRef Medline

3. Sando I, Baker B, Black FO, et al. Persistence of stapedial artery in trisomy 13-15 syndrome. Arch Otolaryngol 1972;96:441-47 CrossRef Medline

4. Marano GD, Horton JA, Gabriele OF. Persistent embryologic vascular loop of the internal carotid, middle meningeal, and ophthalmic arteries. Radiology 1981;141:409-10 CrossRef Medline

5. Diamond $M K$. Unusual example of a persistent stapedial artery in a human. Anat Rec 1987;218:345-54 CrossRef Medline

6. Moreano EH, Paparella MM, Zelterman D, et al. Prevalence of facial canal dehiscence and of persistent stapedial artery in the human middle ear: a report of 1000 temporal bones. Laryngoscope 1994;104:30920 CrossRef Medline

7. Kawai K, Yoshinaga K, Koizumi M, et al. A middle meningeal artery which arises from the internal carotid artery in which the first branchial artery participates. Ann Anat 2006;188:33-38 CrossRef Medline

8. Baron SH. Persistent stapedial artery, necrosis of the incus, and other problems which have influenced the choice of technique in stapes replacement surgery in otosclerosis. Laryngoscope 1963;73:769-82 CrossRef Medline

9. House HP, Patterson ME. Persistent stapedial artery: report of two cases. Trans Am Acad Ophthalmol Otolaryngol 1964;68:644-46 Medline

10. Maran AG. Persistent stapedial artery. J Laryngol Otol 1965;79:97175 CrossRef Medline

11. Davies DG. Persistent stapedial artery: a temporal bone report. $J$ Laryngol Otol 1967;81:649-60 CrossRef Medline

12. Steffen TN. Vascular anomalites of the middle ear. Laryngoscope 1968;78:171-97 CrossRef Medline

13. Marion M, Hinojosa R, Khan AA. Persistence of the stapedial artery: a histopathologic study. Otolaryngol Head Neck Surg 1985;93:298-312 CrossRef Medline

14. Boscia R, Knox RD, Adkins WY, et al. Persistent stapedial artery supplying a glomus tympanicum tumor. Arch Otolaryngol Head Neck Surg 1990;116:852-54 CrossRef Medline

15. Pahor AL, Hussain SS. Persistent stapedial artery. J Laryngol Otol 1992;106:254-57 CrossRef Medline

16. Govaerts PJ, Marquet TF, Cremers WR, et al. Persistent stapedial artery: does it prevent successful surgery? Ann Otol Rhinol Laryngol 1993;102:724-72 CrossRef Medline

17. Wardrop P, Kerr AI, Moussa SA. Persistent stapedial artery preventing successful cochlear implantation: a case report. Ann Otol Rhinol Laryngol Suppl 1995;166:443-45 Medline

18. Jain R, Gandhi D, Gujar S, et al. Case 67: persistent stapedial artery. Radiology 2004;230:413-16 CrossRef Medline

19. Yamamoto E, Hirono Y. Persistent stapedial artery associated with otosclerosis. ORL J Otorhinolaryngol Relat Spec 1988;50:38284 CrossRef Medline

20. Hogg ID, Stephens CB, Arnold GE. Theoretical anomalies of the stapedial artery. Ann Otol Rhinol Laryngol 1972;81:860-70 CrossRef Medline

21. Guinto FC Jr, Garrabrant EC, Radcliffe WB. Radiology of the persistent stapedial artery. Radiology 1972;105:365-69 CrossRef Medline

22. Teal JS, Rumbaugh CL, Bergeron RT, et al. Congenital absence of the internal carotid artery associated with cerebral hemiatrophy, absence of the external carotid artery, and persistence of the stapedial artery. Am J Roentgenol Radium Ther Nucl Med 1973;118:53445 CrossRef Medline

23. Lasjaunias $P$, Moret J, Manelfe C, et al. Arterial anomalies at the base of the skull. Neuroradiology 1977;13:267-72 CrossRef Medline
24. Lasjaunias P, Moret J. Normal and non-pathological variations in the angiographic aspects of the arteries of the middle ear. Neuroradiology 1978;15:213-19 CrossRef Medline

25. Rodesch G, Choi IS, Lasjaunias P. Complete persistence of the hyoido-stapedial artery in man. Case report. Intra-petrous origin of the maxillary artery from ICA. Surg Radiol Anat 1991;13:63-65 CrossRef Medline

26. Sheikh BY, Coates R, Siqueira EB. Stapedial artery supplying sphenoid wing meningioma: case report. Neuroradiology 1993;35:537-38 CrossRef Medline

27. Diamond MK. Homologies of the meningeal-orbital arteries of humans: a reappraisal. J Anat 1991;178:223-41 Medline

28. Diamond MK. Homologies of the stapedial artery in humans, with a reconstruction of the primitive stapedial artery configuration of Euprimates. Am J Phys Anthropol 1991;84:433-62 CrossRef Medline

29. Falk D. Meningeal arterial patterns in great apes: implications for hominid vascular evolution. Am J Phys Anthropol 1993;92:81-97 CrossRef Medline

30. Hyrtl J. Several human analogies of of the artery Otto discovered running through the stapes in several hibernators. New observations from the field of human and comparative anatomy. Neue beobachtungen aus dem gebieteder menschlichen und vergleichenden anatomie 1836:457-66. In: states MJdö, ed.

31. Padget DH. The development of cranial arteries in the human embryo. Contrib Embryol Carneg Instn 1948;32:205-61

32. Altmann F. Anomalies of the internal carotid artery and its branches; their embryological and comparative anatomical significance; report of a new case of persistent stapedial artery in man. Laryngoscope 1947;57:313-39 Medline

33. Gabriele OF, Bell D. Ophthalmic origin of the middle meningeal artery. Radiology 1967;89:841-44 CrossRef Medline

34. Salamon G, Guerinel G, Demard F. Radioanatomical study of the external carotid artery. Ann Radiol (Paris) 1968;11:199-215 Medline

35. Seeger JF, Hemmer JF. Persistent basilar/middle meningeal artery anastomosis. Radiology 1976;118:367-70 CrossRef Medline

36. Moret J, Lasjaunias $\mathrm{P}$, Theron J, et al. The middle meningeal artery. Its contribution to the vascularisation of the orbit. J Neuroradiol 1977;4:225-48 Medline

37. Merland JJ, Théron J, Lasjaunias $\mathrm{P}$, et al. Meningeal blood supply of the convexity. J Neuroradiol 1977;4:129-74 Medline

38. Moret J, Lasjaunias P, Vignaud J, et al. The middle meningeal blood supply to the posterior fossa (author's transl). Neuroradiology 1978;16:306-07 CrossRef Medline

39. Lasjaunias P, Bereinstein A, ter Brugge K. Surgical Neuroangiography. Berlin: Springer-Verlag; 2001

40. Maiuri F, Donzelli R, de Divitiis O, et al. Anomalous meningeal branches of the ophthalmic artery feeding meningiomas of the brain convexity. Surg Radiol Anat 1998;20:279-84 CrossRef Medline

41. Shah QA, Hurst RW. Anomalous origin of the middle meningeal artery from the basilar artery: a case report. J Neuroimaging 2007;17:261-63 CrossRef Medline

42. Baltsavias G, Kumar R, Valavanis A. The pharyngo-tympano-stapedial variant of the middle meningeal artery. A case report. Interv Neuroradiol 2012;18:255-58 CrossRef Medline

43. Kumar S, Mishra NK. Middle meningeal artery arising from the basilar artery: report of a case and its probable embryological mechanism. J Neurointerv Surg 2012;4:43-44 CrossRef Medline

44. Plas B, Bonneville F, Dupuy M, et al. Bilateral ophthalmic origin of the middle meningeal artery. Neurochirurgie 2013;59:183-86 CrossRef Medline

45. Cvetko E, Bosnjak R. Unilateral absence of foramen spinosum with bilateral ophthalmic origin of the middle meningeal artery: case report and review of the literature. Folia Morphol (Warsz) 2014;73:8791 CrossRef Medline

46. Salem MM, Fusco MR, Dolati $P$, et al. Middle meningeal artery arising from the basilar artery. J Cerebrovasc Endovasc Neurosurg 2014;16:364-67 CrossRef Medline 
47. Kimball D, Kimball H, Tubbs RS, et al. Variant middle meningeal artery origin from the ophthalmic artery: a case report. Surg Radiol Anat 2015;37:105-08 CrossRef Medline

48. Tandler J. Zur Entwickelungsgeschichte der Kopfarterien bei den Mammalia. 1902. Morphol. Jahrbuch, Bd. 30, S 275-373, Taf. 3-5

49. Fuchs H. Zur Entwicklungsgeschichte des Wirbeltierauges. I. Über die Entwicklung der Augengefässe des Kaninchens. Anat Hefte 1905;28:1-251

50. Lasjaunias P, Santoyo-Vazquez A. Segmental agenesis of the internal carotid artery: angiographic aspects with embryological discussion. Anat Clin 1984;6:133-41 CrossRef Medline

51. Margolis MT, Newton TH. Collateral pathways between the cavernous portion of the internal carotid and external carotid arteries. Radiology 1969;93:834-36 CrossRef Medline

52. McLennan JE, Rosenbaum AE, Haughton VM. Internal carotid origins of the middle meningeal artery. The ophthalmic-middle meningeal and stapedial-middle meningeal arteries. Neuroradiology 1974;7:265-75 CrossRef Medline

53. Martins C, Yasuda A, Campero A, et al. Microsurgical anatomy of the dural arteries. Neurosurgery 2005;56(suppl):211-51; discussion 211-51 CrossRef Medline
54. Koenigsberg RA, Zito JL, Patel M, et al. Fenestration of the internal carotid artery: a rare mass of the hypotympanum associated with persistence of the stapedial artery. AJNR Am J Neuroradiol 1995;16 (suppl):908-10 Medline

55. Silbergleit R, Quint DJ, Mehta BA, et al. The persistent stapedial artery. AJNR Am J Neuroradiol 2000;21:572-77 Medline

56. Curnow J. Two instances of irregular ophthalmic and middle meningeal arteries. J Anat Physiol 1873;8:155-56 Medline

57. Musgrove J. Origin of ophthalmic artery from middle meningeal. $J$ Anat Physiol 1893;27:279-81 Medline

58. Chanmugan PK. Note on an unusual ophthalmic artery associated with other abnormalities. J Anat 1936;70(pt 4):580-82 Medline

59. Bossi R, Pisani C. Collateral cerebral circulation through the ophthalmic artery and its efficiency in internal carotid occlusion. $\mathrm{Br} J$ Radiol 1955;28:462-69 CrossRef Medline

60. Hayreh SS, Dass R. The ophthalmic artery: I. Origin and intra-cranial and intra-canalicular course. Br J Ophthalmol 1962;46:65-98 CrossRef Medline

61. Louw L. Different ophthalmic artery origins: embryology and clinical significance. Clin Anat 2015;28:576-83 CrossRef Medline 